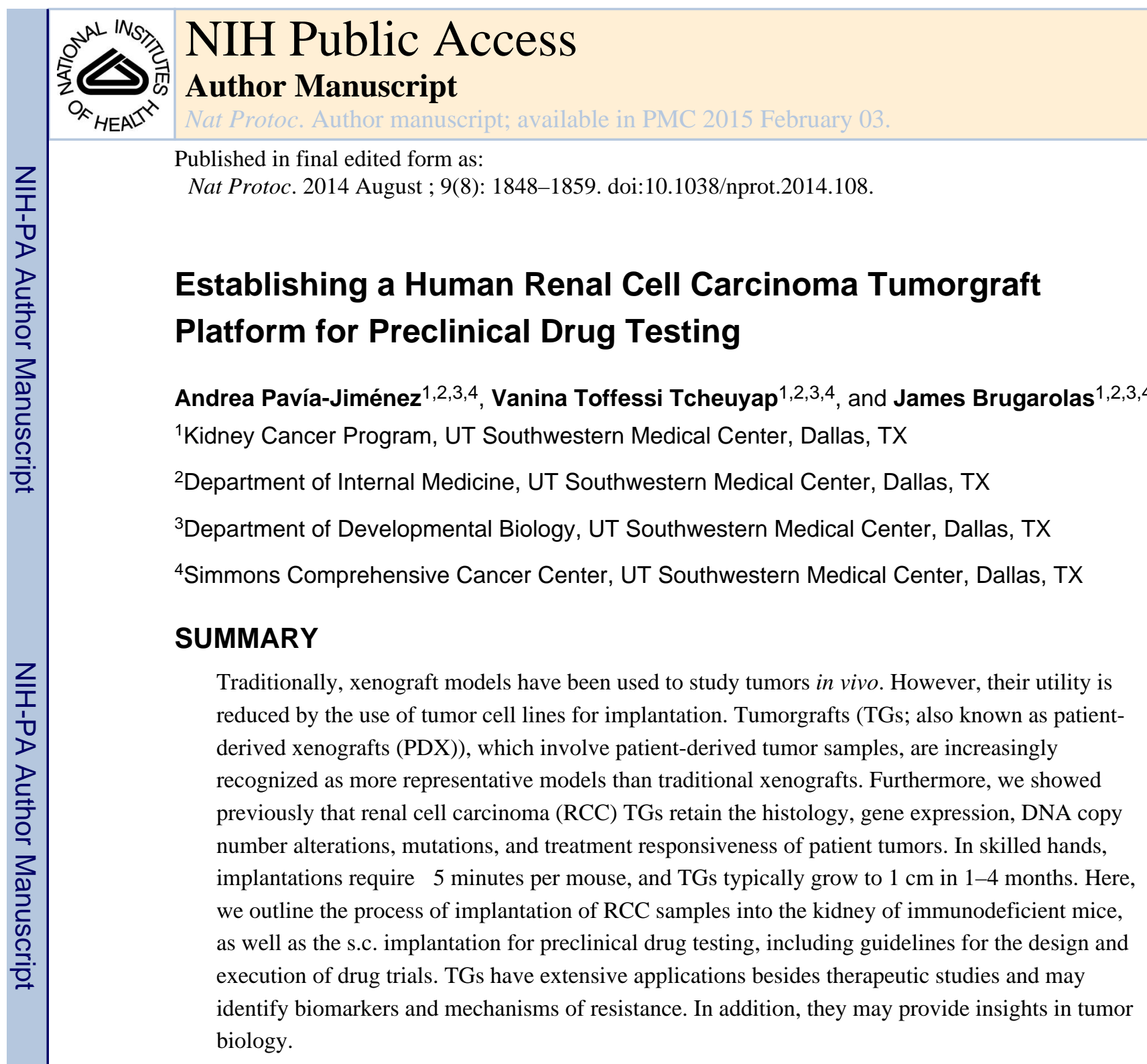

\title{
INTRODUCTION
}

Kidney cancer is among the ten most common cancers in the United States with an estimated 65,150 new cases each year, and 13,680 deaths in 2013 ${ }^{1}$. Most malignant kidney tumors are RCCs, which account for $>90 \%$ of renal malignancies in adults, with a rising incidence $^{2}$. RCC is classified into several subtypes, including clear cell (ccRCC), papillary and chromophobe. Despite recent advances in targeted therapies, metastatic RCC remains largely incurable. One factor hindering drug development is the lack of preclinical models that closely mimic human renal cancer. The inadequacy of current preclinical models is evidenced by the subsequent failure rates of drugs in clinical trials. Less than $20 \%$ of

\footnotetext{
${ }^{\dagger}$ Correspondence should be addressed to J.B. (james.brugarolas@utsouthwestern.edu). COMPETING INTEREST STATEMENT

The authors do not have any competing interests to state. AUTHOR CONTRIBUTIONS STATEMENT

APJ wrote the manuscript with input from other authors. VTT partially wrote the first draft of the manuscript. JB conceived and orchestrated the setup of the tumorgraft platform with assistance from APJ, VTT and other lab members, and contributed to the writing of the manuscript.
} 
anticancer drugs in development receive approval by the U.S. Food and Drug Administration (FDA) ${ }^{3}$. This illustrates the need for better preclinical models that faithfully recapitulate human cancer.

Xenograft models derived from RCC cell lines have been extensively used to study tumor biology as well as determinants of progression and metastasis ${ }^{4-6}$. Available RCC cell lines include 786-O, 769-P, A498, Caki-1 and Caki-2. Despite their contributions, studies with cell lines often fail to accurately predict drug responsiveness in patients, possibly owing to the acquisition of mutations during serial culturing ${ }^{7}$. In fact, DNA copy number analyses of RCC cell lines reveal substantially larger numbers of alterations than in patient-derived tumors $^{8}$. In addition, histology and staging information about the tumors giving rise to the cell lines is sometimes incomplete or inaccurate. For example, the origin of Caki-2 cells is controversial $^{9}$. In an attempt to remedy some of these limitations, models have been developed whereby fresh human tumor samples are implanted into immunodeficient mice. These models are known as TGs or PDXs.

TGs have been found to retain the morphology and molecular characteristics of the original tumors ${ }^{10-19}$. Models have been generated for several cancer types, including pancreatic, prostate, colon, and breast cancers ${ }^{10-13,17-20}$. The implantation of intact tumor fragments into the corresponding organs of immunodeficient rodents may promote growth and preserve the characteristics of the original patient tumors ${ }^{21}$. Orthotopic implantations allow organotypical interactions between tumor cells and the microenvironment in which the tumor $\operatorname{arose}^{22}$.

We have developed a RCC model reproducing the characteristics of patient tumors ${ }^{23}$. Herein, we report our protocol for the generation of RCC TGs. In addition, we describe the s.c. implantation of these TGs for preclinical drug testing along with guidelines for drug trial design and execution.

\section{Applications of the method}

We mainly use this protocol for the preclinical testing of molecularly targeted therapies for RCC. In order to accurately evaluate drug treatment, TGs must faithfully resemble a patient's tumor. We have shown that our TGs preserve: (i) histology, (ii) gene expression, (iii) DNA copy number alterations, (iv) mutations, and (v) treatment responsiveness of renal cancer in humans ${ }^{23}$. Furthermore, paraneoplastic syndromes - conditions that the tumor induces in the host, such as hypercalcemia - are also reproduced in this model ${ }^{23}$.

Our TG model has made possible substantial advances in the understanding of the molecular genetics of ccRCC. Most notably, it facilitated the discovery that BAP1 (encoding BRCA1 associated protein-1) suppressor gene in this cancer type ${ }^{24}$. In patient tissues, contamination from normal human stroma, which dilutes tumor DNA, hinders the detection of mutations (for example, see Figure 1) ${ }^{24,25}$. Inasmuch as human stroma is replaced by the host in our TGs, Sanger sequencing (with human-specific primers), gene expression microarrays, and SNP arrays (for copy number analyses) more accurately reflect what happens in the patient tumor $^{24}$. Thus, analyses in TGs are more sensitive and accurate ${ }^{23-25}$ (for example, see Figure 1). 
A fundamental problem in oncology is the variability in tumor responsiveness to treatment, which may be due, at least in part, to intra-patient tumor heterogeneity. Tumor heterogeneity has been well documented in ccRCC, a subtype accounting for $>70 \%$ of all RCC. Gerlinger et al. ${ }^{26,26}$ demonstrated substantial mutation heterogeneity in ccRCC by using a combination of exome sequencing and extensive sampling. By implanting small samples from the patient tumor and sampling multiple areas, TGs provide a means to further dissect tumor heterogeneity and evaluate its implications in drug resistance.

Compared to xenografts derived from established cell lines, which are few in number, the repertoire of TGs is much wider. TGs can be generated from many patients. Most of the samples are obtained from primary tumors, and perhaps expectedly, many do not engraft. Overall, 10-15\% of implanted tumor samples engraft and thrive long term. Importantly, the tumors that engraft tend to be the most aggressive and are associated with poor patient outcome $^{23}$. Engraftment rates are substantially higher when metastasis (rather than primary tumors are used), indicating that tumors that have acquired the ability to seed distant sites are also more likely to thrive when implanted in another organism ${ }^{23}$. Despite the low engraftment rates, this approach provides a large number and diverse set of lines with different histologies ${ }^{23}$. These TGs allow the evaluation of drugs in clinically relevant by taking hyphen out models and may assist in drug development ${ }^{10}$. Such a colony may aid in biomarker discovery and could be deployed for personalized medicine.

Approaches similar to the ones outlined herein may be used to generate other tumorgraft models. Although there is value in the placement of tumors in their natural (orthotopic) environment, the kidney has long been recognized as an optimal site for tumor engraftment and this protocol is applicable to the implantation of samples from any tumor type under the kidney capsule.

\section{Limitations}

A fundamental problem in oncology is tumor heterogeneity. TGs, which are derived from a small area of the tumor, are unlikely to capture tumor heterogeneity. However, TGs would harbor truncal driver mutations and if a TG is resistant to a particular drug, the corresponding patient tumor is similarly likely to have resistant clones.

Another limitation of TGs is that the tumors that engraft tend to be most aggressive, and thus they are skewed. We have found that tumors derived from metastatic sites tend to engraft at higher frequencies $(50-80 \%)$, however, those from primary sites engraft at far lower frequencies $(14 \%)^{23}$. There is a correlation between the acquisition of metastatic potential by the tumor and engraftment in mice ${ }^{23}$ and we believe that many tumors that fail to engraft are tumors that lack the capacity to seed and thrive at distant sites (or in other organisms).

In addition, engraftment rates are somewhat unpredictable. Necrotic samples or those with few tumor cells may not engraft at all, and it is challenging to predict timing of growth.

A further limitation is the use of NOD/SCID mice. This strain develops thymic lymphoma (TL) as early as 3-4 months of age (although usually not until 8 months of age). Mice should be monitored for TL symptoms (i.e., panting, bulged eyes and enlarged spleen) at 
time of euthanasia (Supplementary Figure 1). Malignant lymphocytes can infiltrate the kidney and may be misinterpreted as a $\mathrm{TG}^{12}$. For this reason, we examine a sample between each serial passage to ensure the absence of TL cells and to correlate TG histology to the patient histology (Figure 2). Although male and female NOD/SCIDs may be used for this procedure, males develop TL at lower rates compared with females and may be preferable for some studies that require longitudinal follow-up.

\section{Experimental Design}

Collection and manipulation of RCC surgical specimens-In our protocol, RCC human tumor samples are obtained from patients diagnosed with a renal mass greater than 7 $\mathrm{cm}$; multiple, bilateral or recurrent tumors; tumors suspected of invasion on imaging studies; or those associated with regional lymphadenopathy and/or distant metastasis. We adopted these criteria to select for tumors with higher chances of engraftment ${ }^{23}$. Patients provide written informed consent and enroll in a protocol approved by the Institutional Review Board (IRB) that utilizes otherwise discarded tissue from surgeries. It is important that a clinical pathologist provide the specimens so that diagnosis is not affected and it is ensured that the specimen contains mostly tumor cells. If genetic studies are intended, it is also fitting to collect samples from adjacent normal kidney (or blood) ${ }^{25}$. Handling of human samples should be performed in accordance with Biosafety Level 2 standards.

The tumors should be collected in sterile conditions and transported on ice. Ideally, they should be processed as soon as possible after surgical removal to maximize tumor viability and reduce the likelihood of bacterial contamination. In our experience, processing in less than $2 \mathrm{~h}$ is adequate, but we have not systematically evaluated how timing affects tumor viability. Processing consists of transferring the patient tumor sample into a petri dish containing $1 \%$ (vol/vol) penicillin/streptomycin (pen-strep) solution dissolved in PBS and cutting fragments for: (i) Implantation (15 fragments with diameter of $2 \mathrm{~mm}$ ), (ii) long-term preservation in DMSO (30 fragments of $2 \mathrm{~mm}$ ), (iii) H\&E (3-5 mm fragments), and (iv) flash freezing for molecular studies (1-2 fragments of $5 \mathrm{~mm}$ ). We avoid disaggregation or the use of confounding additives, such as Matrigel. This process should be performed under sterile conditions, which is critical to preventing infection in a colony of immunocompromised mice.

Tumor implantation in mice and drug trials-RCC tumor tissues can be implanted either orthotopically or subcutaneously. We use non-obese diabetic/severe combined immunodeficient (NOD/SCID) mice, which are deficient in B and T cells and have impaired NK cells. We typically implant primary patient tumor samples under the renal capsule (orthotopically). Once tumors develop, the TG tissue can be implanted s.c. in the left flank. Subcutaneous tumors are more suitable for conducting drug trials because they allow accurate measurement of tumor size over time, which facilitates the assessment of drug efficacy. Although we typically conduct drug trials using tissue from early passages (cohorts), and we have limited in experience with late cohorts, drug trials with the same TG in both early and late cohorts have shown similar results (data not shown), In our experience, 28 days of treatment provides a suitable timeframe for drug trials, particularly 
when the time frame is sufficient for a more than threefold increase in the tumor volume of vehicle-treated mice.

Ideally, pharmacokinetic (PK) studies are conducted before any drug trials to determine that adequate circulating levels will be achieved and to adjust drug exposures to those expected in humans (if known). Optimally, they are conducted on non-tumor bearing mice of the same strain, age and sex as those for drug trials. During PK studies, mice are euthanized at different time points following drug administration and blood is collected to measure drug levels using mass spectrometry. Defined amounts of the drug are used as a reference. This information is used to determine the maximal concentration $\left(\mathrm{C}_{\max }\right)$, drug exposure (AUC, area under the curve $)$ and trough levels $\left(\mathrm{C}_{\min }\right)$. More detailed information as well as PK studies of two therapies we have investigated using this protocol, sunitinib and sirolimus, can be found elsewhere ${ }^{23}$.

The implantation of tumors into immunodeficient mice should be performed according to the relevant Institutional Animal Care and Use of Committee (IACUC) guidelines. Special care is required while handling animals, including clean personal protective equipment (PPE), and sterile gloves. The preservation of sterile conditions is crucial to preventing bacterial or fungal infections. After implantation, mice should be monitored daily and, if orthotopically implanted, palpated weekly. In particular, mice implanted with tumors from patients with paraneoplastic hypercalcemia should be monitored very closely, as paraneoplastic hypercalcemia also develops in mice and the mice may develop seizures and die unexpectedly.

Database maintenance-A crucial aspect of building a TG colony is the development of a database that captures patient and TG information. We use a password-protected excel file that can only be accessed by pertinent personnel associated with the IRB-approved protocol. When approved by the IRB, it is most helpful to retain identifiers, which allow going back to the medical record when necessary. For instance, when we discovered that some mice were dying from paraneoplastic hypercalcemia, we were able to go back and determine that the patients who had donated the tumors had also experienced the same paraneoplastic syndrome.

Our database is composed of four main tabs: surgeries, modified, tumorgrafts, and sacrificed tumorgrafts (Supplementary Table 1; version provided is simplified). The surgeries tab lists patients at our institution with planned surgeries for the removal of primary or metastatic RCC. Although we only implant tissue from patients meeting the criteria outlined in the methods, tissue is routinely collected from all consenting patients undergoing surgery. The surgeries tab captures patient demographics (i.e. age, gender, race, and family history of RCC) as well as radiology and pathology information. This tab is color-coded to identify patients from whom tissue was collected and those whose tissue was implanted (black for non-implanted and blue for implanted). The information for all patients whose tumors are implanted (blue) is then copied onto to the 'modified' tab. The 'modified' tab includes most of the information in the surgeries tab, plus additional clinical data, including actual

Supplementary Table 1. Database tabs to facilitate colony maintenance. 
procedure performed, and information about the tumorgrafts. The tumorgraft tab contains information for all currently implanted mice in the colony such as tumorgraft number, cohort, ear tag number, and the presence of a palpable tumor. This tab is essential for tracking tumor growth and to determine when each tumor should be passaged for each TG line. Finally, the sacrificed tab includes all the mice that were implanted, but are not currently alive. Once a mouse is sacrificed, the information from the tumorgraft tab is transferred to this tab, which includes additional information obtained at the time of sacrifice (i.e. tumor size, number of mice passaged, presence of enlarged thymus, and tissue storaged). It is critical that such a database be updated in real-time in order to avoid errors

\section{MATERIALS}

CRITICAL Always work under sterile conditions. Always disinfect surfaces with $70 \%$ EtOH or NPD® (see methods).

\section{REAGENTS}

- Human RCC tissue. CAUTION All tissue handling should be done in a Biosafety Level 2 hood. Be careful when working with human tissue; always use gloves and avoid direct skin contact. Assume patients may have been infected with HIV or other highly transmissible organisms. We do not process samples known to carry infections. CRITICAL All work with human material should be accompanied by an informed consent from the donor.

- NOD/SCID mice 4-8 week old. We have also used NOD/SCID $\gamma c$-deficient mice, but have limited experience with this strain. CAUTION All experiments should be performed in accordance with institutional and governmental guidelines and regulations. CRITICAL Always handle mice under a sterile hood and with sterile instruments. Change gloves often if non-sterile objects have been handled and spray with NPD. Never open cages outside of the hood or expose animals to the outside environment.

- HBSS, no calcium, no magnesium, no phenol red (Invitrogen, cat. no. 14175-103)

- PBS, without calcium chloride and magnesium chloride (Sigma-Aldrich, cat. no. D8537)

- Penicillin-Streptomycin, 100x solution (Sigma, cat. No. P0781)

- DMSO (Santa Cruz, cat. no. SC-358801) CAUTION Avoid direct contact as it will cause irritation.

- Isoflurane (Butler Schein, cat. no. 029405) CAUTION Avoid inhalation of anesthetic agent. Avoid contact with skin an eyes, as it will cause irritation.

- Buprenorphine (controlled substance)

- 200 proof ethanol alcohol (Koptec, cat. no. V1001)

- EDTA (Research Products International Corporation, cat. no. 29971) CAUTION Avoid direct contact as it will cause irritation. 
- $\mathrm{NaOH}$ (Research Products International Corporation, cat. no. 31003)

- $\quad \mathrm{NPD} \circledast($ a quaternary ammonium compound formulated with a compatible detergent system;Steris, cat. no. 6390) CAUTION Avoid direct contact as it will cause irritation.

- Formalin buffered phosphate, 10\% (Fisher Scientific, cat. no. SF100-4) CAUTION Avoid direct contact to skin and eye. Use under a fume hood and always use protective equipment (i.e. gloves, goggles, and lab coat).

- Paraffin (McCormick Scientific, cat. no. 39502004)

- Hematoxylin (StatLab, cat. no. SL95-16)

- $\quad$ Eosin Y (StatLab, cat. no. SL98-16)

- Xylene (StatLab, cat. no. 8400-1)

- $\quad$ High Def (StatLab, cat. no. SL103)

- Bluing reagent (Richard Allan Scientific, cat. no. 7301)

- Cytoseal 60 (Thermo Scientific, cat. no. 8310-4)

\section{EQUIPMENT}

- Sterile hood (i.e., a Class II Type A2 hood)

- Medium surgery board (Kent Scientific Co., cat. no. SURG510SS)

- Autoclave

- $\quad$ FST 250 Hot Bead Sterilizer (Fine Science Tools, cat. no. 18000-45)

- Isoflurane vaporizer (Veterinary Anesthesia Systems Summit)

- Oxygen tank

- Universal Rodent Nosecone (Molecular Imaging Products Company, cat. no. AS-01-0525)

- Mask Stabilizer (Molecular Imaging Products Company, cat. no. AA-00-0322)

- Posi-Seal Mouse Induction Chamber (Molecular Imaging Products Company, cat. no. AS-01-0532)

- F/AIR Filter Canister (Harvard Apparatus, cat. no. 600979)

- Heating pad

- Self-sealing sterilization pouches, $13 \times 26 \mathrm{~cm}$ (Fine Science Tools, cat. no. 28000-10)

- $\quad$ PDO Suture 4-0 NSH (Shopmedvet.com, cat. no. MV-Z315)

- Povidone Iodine Swabsticks (Dynarex, cat. no. 9424)

- Sterilized medium prep pads, (70\%, vol/vol; VWR, cat. No. 15648-916)

- Sterile gloves 
- Swann-Morton sterile blades \#24 (Cincinnati Surgical, cat. no. 01SM24)

- AUTOCLIP 9 mm box of 1000 wound clips (Braintree Scientific, cat. no. EZC CS)

- Reflex 9 wound clip applicator (Fine Science Tools, cat. no. 12031-09)

- $\quad$ 12-cm wound clip remover (Fine Science Tools, cat. no. 12033-00)

- $\quad$ Ear Tag Applicator (Fine Science Tools, cat. no. 24220-00)

- Ear tags (Tags Company, cat. no. 1005-1)

- Straight forceps (Fine Science Tools, cat. no. 11002-12)

- Curved forceps (Fine Science Tools, cat. no. 11003-12)

- 10-cm curved spring scissors (Fine Science Tools, cat. no. 15023-10)

- Straight scissors (Fine Science Tools, cat. no. 14028-10)

- Electric trimmer

- Calipers (Fisher Scientific, cat. no. 15077957)

- Balance

- Cryotube vials (Thermo Scientific, cat. no. 375418)

- $\quad$ Sterile petri dishes

- $\quad 0.22-\mu \mathrm{m}$ filter for filtering of all sterile solutions

- Spray bottle

- 1 -ml syringe

- $\quad 25$ - and 27-gauge needles

- Sterile $50-\mathrm{mL}$ conical tubes

- Centrifuge

- Upright microscope

- Microm STP 120 Spin Tissue Processor

- HistoStar Embedding workstation (Thermo Scientific, cat. no. A81000002)

- Rotary microtome (Leica Biosystems, cat. no. RM2235)

- Solvent-resistant marker (Fisher Scientific, cat. no. 14-905-30)

- Tissue-Loc HistoScreen cassettes (Thermo Scientific, cat. no. C-1000-AQ)

- Disposable base molds (Thermo Scientific, cat. no. 41741)

- Microtome blade (Thermo Scientific), cat. no. MX35)

- Flotation bath (Fisher Scientific, cat. no. 135)

- Microscope slides (Fisher Scientific, cat. no. 12-550-17)

- Coverslips (StatLab, cat. no. SL102450) 


\section{REAGENT SETUP}

CRITICAL All solutions must be prepared and aliquoted in a sterile hood.

- $1 \%$ (vol/vol) pen-strep solution in PBS. Add $5 \mathrm{~mL}$ of pen-strep solution to a 500$\mathrm{ml}$ bottle of sterile PBS. Once prepared, it can be stored at $4^{\circ} \mathrm{C}$ for up to 4 weeks.

- $10 \%$ (vol/vol) DMSO/HBSS. Add $50 \mathrm{~mL}$ of DMSO to a $450 \mathrm{~mL}$ bottle of sterile HBSS. Mix solution and filter using a $0.22-\mu \mathrm{m}$ filter. Once prepared, it can be stored at $4{ }^{\circ} \mathrm{C}$ indefinitely. CAUTION If this solution gets contaminated it will have devastating consequences, so it is recommended that it be handled with particular care and replaced every 3 months.

- $\quad 70 \%$ (vol/vol) ethyl alcohol. Mix 7 parts alcohol and 3 parts double-filtered water and transfer to a spray bottle. Can be stored at room temperature indefinitely.

- Buprenorphine solution. Transfer $1 \mathrm{~mL}$ of Buprenorphine $(0.3 \mathrm{mg} / \mathrm{mL})$ to a sterile $50 \mathrm{~mL}$ conical tube. Bring volume up to $20 \mathrm{~mL}$ by adding sterile PBS. Solution can be stored at room temperature for up to 6 months. Once you have determined the number of mice to implant, add appropriate amount of Buprenorphine solution (100 $\mu \mathrm{L}$ per mouse) in a $1 \mathrm{~mL}$ syringe with a 27 gauge needle before beginning procedure. CRITICAL STEP Preparing this prior to surgical procedure will ensure that you have the Buprenorphine solution ready to inject before the mouse wakes up from anesthesia.

- EDTA solution. Dissolve $7.3 \mathrm{~g}$ of EDTA into approximately $40 \mathrm{~mL}$ of sterilized water by placing on a rocker until crystals dissolve. Check $\mathrm{pH}$ using a calibrated $\mathrm{pH}$ meter. Adjust $\mathrm{pH}$ to 8.0 using a small amount of $\mathrm{NaOH}$ and bring volume up to $50 \mathrm{ml}$ by adding more sterile water. Filter through a $0.22 \mu \mathrm{m}$ filter into a fresh 50 $\mathrm{ml}$ conical tube. EDTA can be stored at room temperature until crystals start to precipitate out of solution.

- NPD solution. Dilute $1 / 2$ fluid ounce of stock NPD solution into a gallon of water. It can be stored at room temperature for up to 2 weeks. Allow 10-minute contact time to disinfect. CAUTION Avoid direct contact with skin and eyes.

\section{EQUIPMENT SETUP}

- Fresh tissue processing. Time from sample removal from the patient to tissue processing should not exceed $2 \mathrm{~h}$. This timing is critical, as tissue will quickly deteriorate after blood supply is cut off. Autoclave all instruments in sterilization pouches prior to use. When working with human samples, discard all waste in biohazard containers. Always work under a sterile Biosafety Level 2 hood. Spray all items with either NPD or 70\% ( $\mathrm{vol} / \mathrm{vol}$ ) ethanol before bringing them in the hood.

- Setup for surgical procedure. We set up instruments for the surgical procedure as shown in Supplementary Figure 2. Autoclave all instruments in sterilization pouches before surgery: forceps, scissors, fine surgical scissors, sharp forceps, etc. Spray the hood with NPD. Spray all objects coming into hood for surgery with 
NPD. This includes heating pad, surgery board, induction chamber, shaver, and the outside of all wrapped instruments. Use different sets of instruments for all external (i.e. skin) and internal (i.e. body wall and kidney) handling. Failure to do so may result in infection to the mouse. If 'internal' instruments have been used on 'external' areas they need to be cleaned by wiping with an alcohol pad and placing in hot bead sterilizer for 20 seconds. Pick up instruments from the top to avoid getting burned or contaminating the instruments, and cool for 2 minutes on inner surface of autoclave bag until cool enough to use on mice. Do not use hot instruments on mice as it will cause burns.

\section{PROCEDURE}

\section{Selecting tissue from qualifying patients}

1 Obtain appropriate tissue. It is recommended to implant tissues from patients with aggressive tumors. We have defined aggressiveness to be tumors greater than $7 \mathrm{~cm}$, bilateral or recurrent tumors, with suspicion of invasion, lymphadenopathy (lymph nodes greater than $1 \mathrm{~cm}$ in shortest axis), or distant metastasis. CAUTION For safety reasons, we exclude patients with known HIV or Hepatitis B or C infections. CAUTION All procedures with human samples should be performed following Biosafety Level 2 standards.

\section{Collection and processing of fresh patient tissue TIMING $2 \mathrm{~h}$}

CRITICAL Autoclave all instruments in sterilization pouches prior to use. When working with human samples, discard all waste in biohazard containers. Always work under a sterile Biosafety Level 2 hood. Spray all items with either NPD or 70\% (vol/vol) ethanol before bringing them into the hood.

2 Place tissue in a tube containing $\sim 10 \mathrm{~mL}$ of HBSS solution and place it on ice. Proceed to step 3 as soon as possible. CRITICAL STEP Keep tissue moist and cold to preserve until processing. CRITICAL STEP Time from sample removal from the patient and tissue processing should not exceed $2 \mathrm{~h}$. This timing is critical, as tissue will quickly deteriorate after blood supply is cut off.

3 Place tissue in a sterile hood. Pick up the tissue using a pair of sterile autoclaved forceps and transfer to a sterile p150 dish containing $10 \mathrm{~mL}$ of sterile $1 \%$ (vol/ vol) pen-strep solution in PBS.

$4 \quad$ By using sterile forceps and a razor blade remove any tissue that appears normal or necrotic, or which is clearly heterogeneous. Tumor tissue is fleshy, while necrotic tissue is often yellow and breaks apart easily when touched. CRITICAL STEP Often the tissue available may not be large enough to store for all purposes outlined below (i.e. flash frozen, formalin, and DMSO samples). Prioritize tissue processing according to specific project needs.

5 Cut a 3-5 mm fragment to place in a vial (we typically use a screw-cap cryovial) with formalin. Perform histological analysis of this sample as described in Box 1 
to confirm the presence of tumor cells (Figure 3). CAUTION. Be careful not to expose skin to formalin.

6 Cut $\sim 45$ fragments $\sim 2 \mathrm{~mm}$ in diameter from the remaining tumor tissue. Split 15 fragments into three $1.5 \mathrm{ml}$ cryovials. Label cryovials with deidentified 'TG ID', and 'for implantation' and place on ice (be sure to add $~ 100 \mu \mathrm{L}$ of sterile $1 \%$ (vol/vol) pen-strep solution in PBS to the tube to keep the tissue moist).

CRITICAL STEP No identifiers that can be traced back to the patient should be on any tubes, such as name, initials or date of birth. Do not allow tissue to become dry. CRITICAL STEP Do not implant any fragments that float as this may be fat.

7 Label 2 additional cryovials 'TG ID' and 'DMSO' and place 15 tumor fragments in each. Add $1 \mathrm{~mL}$ of cold 10\% (vol/vol) DMSO/HBSS from an aliquot to the tissue in each cryovial, and the transfer of cryovials to wet ice. CRITICAL STEP. DMSO solution must be kept cold at all times to protect damage to cell membrane. CRITICAL STEP. Samples should be transferred to a $-80^{\circ} \mathrm{C}$ freezer within 10 minutes of adding the DMSO solution. Plan the addition of DMSO solution accordingly.

8 Place any remaining tissue in a 1.5-ml cryovial. Label with 'TG ID' and 'flash frozen'. Freeze 'flash frozen' sample by placing in liquid nitrogen and transfer to $-80^{\circ} \mathrm{C}$ for permanent storage. This tissue can be used for protein or genetic analysis as previously described ${ }^{25}$.

9 Place the DMSO samples (from step 7) at $-80^{\circ} \mathrm{C}$ within 10 minutes of adding the $10 \%$ (vol/vol) DMSO in HBSS solution. Proceed to step 10. Remember to transfer the DMSO tube from $-80^{\circ} \mathrm{C}$ to liquid nitrogen for permanent storage between $24 \mathrm{~h}$ to one week later. CRITICAL STEP. Do not place immediately in liquid nitrogen. Tissue must be frozen slowly to preserve cell viability for future implantations. Slow freezing approaches at $-80^{\circ} \mathrm{C}$ may increase tissue preservation.

\section{Renal capsule implantation TIMING 15-30 min per mouse (5 min per mouse in skilled hands)}

10 Anesthetize a mouse with an isoflurane vaporizer by placing it in the induction chamber. Once mouse is fully anesthetized (unresponsive and not blinking; Figure 4a), place it on a tilted surgical board on top of a heating pad. Place the isoflurane cone on the mouse's snout. CRITICAL STEP The mouse needs to be on the heating pad during the entire procedure. Lack of heating may cause hypothermia.

11 Shave off the fur from its back (Figure 4b). Make sure that shaver has a sharp blade. CAUTION Do not apply too much pressure while shaving as this may harm the skin. Mouse skin should not be injured while shaving.

12 Apply iodine and let it be absorbed into the skin, then wipe with alcohol pad. 
13 Lift back skin with 'external' curved forceps and create a 1-cm incision by cutting along spine with 'external' scissors (Figure 4b).

14 Using the 'internal' pair of scissors, blunt dissect towards the left hind leg (Figure 4c). Introduce the tip of scissors (preferably blunt-ended) in the incision site and slightly open them to separate the body wall from the skin. Retract the scissors from the incision with closed blades. CAUTION Opening and closing scissors inside the mouse can cause damage and bleeding.

15 Place mouse on side and view location of kidney through body wall.

16 With 'internal' instruments, make a small transverse incision in the body wall slightly longer than the long axis of the kidney, $\sim 1 \mathrm{~cm}$. TROUBLESHOOTING

17 Apply pressure on both sides of abdomen with your forefinger and thumb and exteriorize the kidney (Figure 4d). If working with female mice, removal of kidney is done by gently pulling on the fat pad at the base, which also contains the ovaries. CAUTION Make sure not to damage the ovaries - this will cause bleeding. Allow the kidney to rest on the body wall.

18 Make a 2-4 mm incision (dorsal, caudal to rostral) in the capsule with curved spring-loaded scissors. Create a pocket between the capsule and underlying parenchyma (Figure 4e). CAUTION Do not damage parenchyma which will bleed if damaged. CRITICAL STEP Keep scissors as close to the renal capsule as possible while also being careful not to rip the capsule.

19 Implant two or three pieces of $2 \times 2 \times 2 \mathrm{~mm}$ tumor tissue (from step 6 , one at a time) into the pocket under the capsule with a pair of fine forceps. The capsule should appear transparent and grafts within the kidney should be visible (Figure $4 \mathrm{f}$ and $\mathrm{g}$ ). CRITICAL STEP Note that if the tissue is not visible under the capsule engraftment rates may be reduced. TROUBLESHOOTING

20 When grafting is complete, gently ease the kidney back into the body cavity. Suture body wall with absorbable suture. Apply two continuous stitches and tie the loose ends with two knots (Figure 4h).

21 Apply staples, making sure that the skin is completely closed (Figure 4i). CRITICAL STEP Do not staple the body wall and skin together as this will cause a painful swelling.

22 Spray the back of the neck with $70 \%$ ( $\mathrm{vol} / \mathrm{vol}$ ) ethanol. Pinch the scruff on the back of the neck; this will make a pocket between the pinched skin. Insert needle and inject $100 \mu \mathrm{L}$ of Buprenorphine dilution s.c. (Figure $4 \mathrm{j}$ and $\mathrm{k}$ ). CRITICAL STEP Administer Buprenorphine after the surgery and the following morning. Record Buprenorphine usage in a ledger. CRITICAL STEP Buprenorphine is a controlled substance and its use must be meticulously monitored and recorded according to IACUC policy.

23 By using the ear tag applicator, grab the ear tag from the sleeve. Apply ear tag to the mouse before it wakes up. 
24 Monitor mice every two days after surgery until removal of staples. Staple removal can be done $7-14 \mathrm{~d}$ after surgery.

25 After removing the staples, monitor tumor growth by palpation at least weekly. Tumors may develop 14-180 d from surgery. Once a tumor reaches at least $\sim 7$ $\mathrm{mm}$ by palpation, proceed to the next step to passage to subsequent cohorts. CAUTION Do not let the tumors exceed $1-1.5 \mathrm{~cm}$. Large tumors are painful to the mice and will cause death.

\section{Harvesting and passaging tissue TIMING 15-30 min per mouse (5 min per mouse in skilled hands)}

26 Anesthetize the tumor-bearing mouse by using a 50-ml conical tube with paper towel fragments soaked in isoflurane. Do not anesthetize mouse using the induction chamber used for implantation CRITICAL STEP We avoid using the induction chamber for terminal procedures in an effort to minimize infection of mice subjected to survival surgeries.

27 Check level of anesthesia by toe-pinching. Once the mouse no longer responds to toe-pinching, if desired, collect blood by cardiac puncture (Figure 5a). Blood may be useful for cell counts, chemistries, metabolic studies and the identification of biomarkers. To collect blood, use a 1-ml syringe with a 25gauge needle to draw approximately $10 \mu \mathrm{L}$ of EDTA solution. Lay mouse supine and spray chest and abdomen with $70 \%$ (vol/vol) ethanol. Locate sternum and insert needle directly below and parallel to sternum on the left side about 30 degrees from the horizontal to a depth of $\sim 1 \mathrm{~cm}$. Slowly draw up to $1 \mathrm{~mL}$ of blood into the syringe. CRITICAL STEP To ensure a proper blood draw, the process should be performed slowly and carefully. Multiple attempts to draw blood may cause hemolysis. Expel blood from syringe into 1.5-ml tube and place tube on ice until the procedure is finished. TROUBLESHOOTING

28 After any blood has been collected, dislocate the cervical spine to ensure death by placing index finger and thumb behind the skull and pulling the body by the base of the tail. You will feel the spine separating from the head. CRITICAL STEP Death must be ensured before opening the mouse to extract the tumor.

29 Place the mouse in a supine position and spray abdomen with $70 \%$ (vol/vol) ethanol. Use forceps and scissors to make a midline incision down the body to expose the organs.

30 Use a new sterile set of instruments to locate the left kidney with the growing tumor (Figure 5b). CAUTION Be careful not to cut the bowel when extracting the tumor-bearing kidney, as this may expose it to bacteria.

31 Place the kidney with the tumor in a p150 dish containing 10 $\mathrm{mL}$ of sterile $1 \%$ (vol/vol) pen-strep in PBS. Bisect the kidney and remove all normal kidney from the specimen (Figure $5 \mathrm{c}$ and d). CRITICAL STEP Do not implant normal kidney into subsequent cohorts of mice. 
32 Either perform orthotopic passaging by repeating steps 10-31 (orthotopic processing can be continued indefinitely), proceed to s.c. implantation for a drug trial, or store the tissue. Tissue can also be implanted from the sample stored in DMSO at step 7 if required, to do this, follow the guidelines in Box 2.

33 Once all surgical procedures have been completed, spin the blood collected at step 27 at $3000 \times g$ for $10 \mathrm{~min}$. Collect plasma and transfer to a new cryovial. Store it at $-80^{\circ} \mathrm{C}$ indefinitely.

\section{Implantation for drug trials TIMING 2-3 min per mouse}

34 Take fresh TG tissue after collection and cut $4 \times 4 \times 4 \mathrm{~mm}$ fragments to be implanted s.c. into as many mice as needed for a drug trial. CRITICAL STEP If more than one mouse's tumor is required for drug trial implantation it is best to select mice in the same cohort (derived from the same initial patient tumor fragment) with a similar tumor size. This will reduce differences in tumor growth rates. TROUBLESHOOTING

35 Perform steps $10-14$ on a mouse.

36 With the 'internal' pair of scissors, separate dermis from the body wall. Do not open the scissors insert them to make a tunnel underneath the skin towards the left hind leg (Figure 6a). CRITICAL STEP Opening scissors will allow the tissue to freely move once inserted. This can cause difficulties in measuring the tumors.

37 Pick up a $4 \times 4 \times 4 \mathrm{~mm}$ tissue fragment from step 34 with the 'internal' straight forceps and place underneath the skin (Figure 6b). CRITICAL STEP Make sure to avoid any contact between tumor fragment and skin as this may introduce bacteria.

38 By using an 'external' set of curved forceps, hold the site of insicion. Using another set of 'external' forceps, push tumor down the flank of the mouse on the outside of the skin towards the hind leg (Figure 6c). CRITICAL STEP Ensure that the tumor fragment is far away from the incision site to prevent it from being stapled to the skin.

39 Apply staples making sure that the skin is completely closed.

40 Administer $100 \mu \mathrm{l}$ buprenorphine immediately after surgery. It is not necessary to administer another dose the following day.

41 Monitor mice every $2 \mathrm{~d}$ after surgery until removal of staples. This can be done 7-14 days after the surgery. After $14 \mathrm{~d}$ of implantation, and once staples are removed, proceed to the next step to begin to measure tumors.

\section{Tumor measurements for drug trials TIMING 2-3 minutes per mouse}

42 Pick up the mouse by holding its tail. To do this, place the mouse on the wire bars of the cage lid to get a good grip. Hold the mouse's tail with your dominant hand. With your non-dominant hand, cup the mouse. By using the thumb and 
first finger, hold the scruff on the back of the neck behind the ears firmly. Tuck the tail between your last two fingers, so that the spine of the mouse is resting next to your knuckles. Once the mouse is securely restrained in your nondominant hand, pick the mouse up.

43 With the help of calipers, measure the largest length of the tumor, then the largest perpendicular width and finally the depth. Multiply these together to get estimated volume. This formula (length $\times$ width $\times$ depth) minimizes giving excessive weight to a particular dimension, which can introduce a bias.

44 Repeat steps 42 and 43 twice a week until volumes reach $300-500 \mathrm{~mm}^{3}$. When tumors reach this volume, proceed to the next step and allocate mice into treatment arms. CRITICAL STEP The tumors must be allowed to reach at least $300 \mathrm{~mm}^{3}$ to ensure that the tumors are growing. Failure to do this may lead to lack of tumor growth during the trial period, and this could erroneously be interpreted as suppression of growth by the administered drug. In addition, a vehicle control should always be included in drug trials.

45 Separate mice into treatment groups on the basis of the following criteria: tumor volume, growth rate and mouse weight. First, sort the mice by tumor volume. Next, sort the mice by tumor growth rates relative to the first measurement. This may be accomplished on an Excel file by sorting the mice according to tumor fold change with respect to the first tumor measurement. CRITICAL STEP It is important to visually inspect the tumor growth rates, as tumors with a plateau phase may be unsuitable. Finally, obtain the weights of the mice and sort the mice according to weight.

46 Distribute the mice such that each treatment group is as similar as possible according to the aforementioned criteria. CRITICAL STEP If treatment groups are not similar, the data gathered may be uninterpretable or biased.

47 Tag and arrange to house mice in separate cages according to treatment groups. CRITICAL STEP This will minimize the chances of administering the wrong treatment. CRITICAL STEP If mice are too old, and, in particular if they are male, they will fight; females are thus preferable for drug trials.

48 Weigh each mouse and treat with an appropriate volume of drug or vehicle (for controls). Monitor mice regularly and take measurements twice weekly.

49 Treat the mice for $28 \mathrm{~d}$, with route and intervals as determined by PK analyses. Weigh mice once per week during the treatment period and adjust drug volume accordingly. In our experience, treatment for $28 \mathrm{~d}$ is suitable, particularly when that timeframe is sufficient for a greater than threefold increase in the tumor volume in vehicle-treated mice. However, for slower growing tumors, longer drug trials may be required. Proceed to the next step (drug trial termination) at an appropriate time point after the last drug treatment, depending on the information you wish to gain from the final samples obtained. We euthanize mice $2-4 \mathrm{~h}$ after the last drug treatment. CRITICAL STEP This is to ensure high drug levels in tissue and plasma. Alternatively, mice can be sacrificed at trough 
( $1 \mathrm{~h}$ before the next drug dose is scheduled). CRITICAL STEP $28 \mathrm{~d}$ of drug treatment should provide an adequate dynamic range to evaluate therapeutic effects.

\section{Termination of a drug trial TIMING 1-1.5 hours for 20 mice}

50 Weigh the mice.

51 Perform a final tumor measurement through the skin, as described in steps 42 and 43.

52 Anesthetize the mice with isoflurane, perform cardiac puncture and euthanize them (as outlined in steps 26-28), and process blood as described in step 33.

53 If desired, take a digital picture of mouse lying on its abdomen with the tumor area visible (Figure 7).

54 Carefully resect the tumor from the s.c. space. Place tumor on a p150 dish, on top of a white background above a ruler. Write the ear tag number and treatment group below the tumor on the white paper. Be sure that the tumor is aligned with the $0 \mathrm{~cm}$ mark so that the pictures taken are consistent across the treatment groups. Take a picture with the tumor and the ear tag and treatment group visible.

55 Record tumor dimensions of resected tumor and also tumor weights.

56 Retain tumor tissue as appropriate for any further analysis you wish to perform. We cut tumors in half and place in 2 cryovials. We freeze one in liquid nitrogen and add formalin to the other. The frozen tissue can be used to test for drug levels in the tissue, for protein analyses by western blot, and the fixed tissue can be used for histological studies.

\section{TIMING}

- Step 1, Selecting tissue from qualifying patients: variable; depends on the number of patients

- Steps 2-9, Collection and processing of fresh patient tissue: $\sim 2 \mathrm{~h}$

- Steps 10-25: 5-30 min per mouse, depending on experience level

- Steps 26-33: 5-30 min per mouse, depending on experience level

- Steps 34-41: 2-3 min per mouse

- Steps 42-44: 2-3 min per mouse

- Steps 45-49: allocation time may vary substantially, depending on individual project needs

- Steps 50-56: $1-1.5 \mathrm{~h}$ for 20 mice

TROUBLESHOOTING advice can be found in Table 1. 


\section{ANTICIPATED RESULTS}

Tumor heterogeneity, pathologic staging, and timing from removal of blood supply to processing of the tissue may affect latency and engraftment in mice. Although it is difficult to predict which lines will thrive when implanted into immunocompromised mice, in our experience we have an engraftment rate of $14 \%$ for primary tumors. Tumors can be palpated between 14-180 d after implantation. If nothing can be palpated at $180 \mathrm{~d}$, mice may be sacrificed because of the high risk of TL.

Our TGs have been shown to preserve gene expression, DNA copy number alterations and mutations from the originating patient tissue. In addition, these TGs also preserve drug responsiveness and even paraneoplastic syndromes such as hypercalcemia, which leads to seizures and eventually death if not detected early ${ }^{23}$.

We have used this TG model for RCC to test molecularly targeted therapies, for example sunitinib and sirolimus (dominant active metabolite of temsirolimus) and found that this model represents an excellent platform for the testing and evaluation of new drugs ${ }^{23}$. It is important to note, however, that some signaling pathways, such as the HGF/MET pathway, do not cross-react across species and this may affect the results. This model could be used to probe tumor heterogeneity and to mechanisms implicated in drug resistance.

\section{Supplementary Material}

Refer to Web version on PubMed Central for supplementary material.

\section{ACKNOWLEDGEMENTS}

We are thankful to S. Sivanand for her help in establishing the program, P. Kapur for providing RCC histology pictures, and S. Cohn, R. McKay, S. Peña-Llopis, T. Anh Tran, and S. Vega-Rubín-de-Celis for reviewing the manuscript. The work described herein was supported by grants from the American Cancer Society (RSG115739), the V Foundation, the US National Institutes of Health (R01CA175754), and the Cancer Prevention and Research Institute of Texas (RP101075, RP130172 and RP130603) to J.B. as well as a Cancer Center Core grant (1P30CA142543). J.B. is a Virginia Murchison Linthicum Endowed Scholar in Medical Research.

\section{REFERENCES}

1. Siegel R, Naishadham D, Jemal A. Cancer statistics, 2013. CA: A Cancer Journal for Clinicians. 2013; 63:11-30. [PubMed: 23335087]

2. Janowitz T, Welsh SJ, Zaki K, Mulders P, Eisen T. Adjuvant therapy in renal cell carcinoma-past, present, and future. Semin Oncol. 2013; 40:482-491. [PubMed: 23972712]

3. Ocana A, Pandiella A, Siu LL, Tannock IF. Preclinical development of molecular-targeted agents for cancer. Nature reviews. Clinical oncology. 2011; 8:200-209.

4. Nogawa M, et al. Monitoring luciferase-labeled cancer cell growth and metastasis in different in vivo models. Cancer letters. 2005; 217:243-253. [PubMed: 15617843]

5. Liu J, et al. Metformin inhibits renal cell carcinoma in vitro and in vivo xenograft. Urologic oncology. 2013; 31:264-270. [PubMed: 21676631]

6. Ebos JM, et al. Accelerated metastasis after short-term treatment with a potent inhibitor of tumor angiogenesis. Cancer cell. 2009; 15:232-239. [PubMed: 19249681]

7. Rubio-Viqueira B, Hidalgo M. Direct in vivo xenograft tumor model for predicting chemotherapeutic drug response in cancer patients. Clinical pharmacology and therapeutics. 2009; 85:217-221. [PubMed: 19005462] 
8. Beroukhim R, et al. Patterns of gene expression and copy-number alterations in von-hippel lindau disease-associated and sporadic clear cell carcinoma of the kidney. Cancer Res. 2009; 69:46744681. [PubMed: 19470766]

9. Karam JA, et al. Development and characterization of clinically relevant tumor models from patients with renal cell carcinoma. European urology. 2011; 59:619-628. [PubMed: 21167632]

10. Morton CL, Houghton PJ. Establishment of human tumor xenografts in immunodeficient mice. Nature protocols. 2007; 2:247-250.

11. Grisanzio C, et al. Orthotopic xenografts of RCC retain histological, immunophenotypic and genetic features of tumours in patients. The Journal of pathology. 2011; 225:212-221. [PubMed: 21710693]

12. Lawrence MG, et al. A preclinical xenograft model of prostate cancer using human tumors. Nature protocols. 2013; 8:836-848.

13. Kim MP, et al. Generation of orthotopic and heterotopic human pancreatic cancer xenografts in immunodeficient mice. Nature protocols. 2009; 4:1670-1680.

14. Chen K, Ahmed S, Adeyi O, Dick JE, Ghanekar A. Human solid tumor xenografts in immunodeficient mice are vulnerable to lymphomagenesis associated with Epstein-Barr virus. PloS one. 2012; 7:e39294. [PubMed: 22723990]

15. Garber K. From human to mouse and back: 'tumorgraft' models surge in popularity. Journal of the National Cancer Institute. 2009; 101:6-8. [PubMed: 19116380]

16. Monsma DJ, et al. Genomic characterization of explant tumorgraft models derived from fresh patient tumor tissue. Journal of translational medicine. 2012; 10:125. [PubMed: 22709571]

17. Fu XY, Besterman JM, Monosov A, Hoffman RM. Models of human metastatic colon cancer in nude mice orthotopically constructed by using histologically intact patient specimens. Proceedings of the National Academy of Sciences of the United States of America. 1991; 88:9345-9349. [PubMed: 1924398]

18. Garcia PL, et al. Development and histopathological characterization of tumorgraft models of pancreatic ductal adenocarcinoma. PloS one. 2013; 8:e78183. [PubMed: 24194913]

19. DeRose YS, et al. Tumor grafts derived from women with breast cancer authentically reflect tumor pathology, growth, metastasis and disease outcomes. Nat Med. 2011; 17:1514-1520. [PubMed: 22019887]

20. Walters DM, et al. Inhibition of the growth of patient-derived pancreatic cancer xenografts with the MEK inhibitor trametinib is augmented by combined treatment with the epidermal growth factor receptor/HER2 inhibitor lapatinib. Neoplasia. 2013; 15:143-155. [PubMed: 23441129]

21. Hoffman, R. Metastasis Research Protocols Vol. 1070 Methods in Molecular Biology. Dwek, Miriam; Schumacher, Udo; Brooks, Susan A., editors. Vol. Ch. 11. New York: Springer; 2014. p. 141-170.

22. Lee M, Muller F, Aquilanti E, Hu B, DePinho R. Stereotactic orthotopic xenograft injections into the mouse brain. Protocol Exchange. 2012

23. Sivanand $\mathrm{S}$, et al. A validated tumorgraft model reveals activity of dovitinib against renal cell carcinoma. Science translational medicine. 2012; 4:137ra175.

24. Pena-Llopis S, et al. BAP1 loss defines a new class of renal cell carcinoma. Nat Genet. 2012; 44:751-759. [PubMed: 22683710]

25. Pena-Llopis S, Brugarolas J. Simultaneous isolation of high-quality DNA, RNA, miRNA and proteins from tissues for genomic applications. Nature protocols. 2013; 8:2240-2255.

26. Gerlinger M, et al. Intratumor heterogeneity and branched evolution revealed by multiregion sequencing. The New England journal of medicine. 2012; 366:883-892. [PubMed: 22397650]

27. Gerlinger M, et al. Genomic architecture and evolution of clear cell renal cell carcinomas defined by multiregion sequencing. Nat Genet. 2014; 46:225-233. [PubMed: 24487277] 


\section{Box 1: Processing of formalin fixed tissue to confirm presence of tumor cells}

1. Leave tissue to fix in formalin for $24-48 \mathrm{~h}$ at room temperature.

2. Incubate tissue in the following solutions, $45 \mathrm{~min}$ per solution: $50 \%$ ( $\mathrm{vol} / \mathrm{vol}$ ) ethanol, $70 \%$ (vol/ $/ \mathrm{vol}$ ) ethanol, $80 \%$ (vol $/ \mathrm{vol}$ ) ethanol, $2 \times 95 \%$ (vol/ $/ \mathrm{vol})$ ethanol, $3 \times$ xylene, $2 \times$ hot paraffin $\left(62^{\circ} \mathrm{C}\right)$. We do this using a tissue processor. CRITICAL STEP Remove tissue from hot paraffin promptly, as incubation in hot paraffin for an extended period of time will permanently damage tissue.

3. Place tissue in disposable molds and add melted paraffin. Label and cool the tissue for $\sim 15 \mathrm{~min}$ on a cold plate at $-20^{\circ} \mathrm{C}$.

4. Once the tissue has been cooled for $\sim 15 \mathrm{~min}$, remove hardened paraffin block from the disposable mold.

5. Place embedded tissue in a microtome and add a blade. CAUTION Be careful when handling blades and assure it is carefully secured before cutting cassette block.

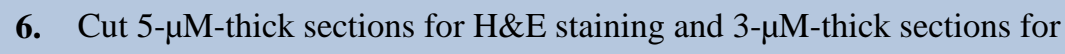
immunohistochemical analysis.

7. Place sections in a $37^{\circ} \mathrm{C}$ water bath and let heat for about a minute.

8. Label slides. Place heated sections on slides.

9. Stain the sections with H\&E. We do this by performing the following: $3 \times 3$ minutes in xylene, $3 \times 1$ minutes in $100 \%$ ethanol, $2 \times 1$ minutes in $95 \%$ (vol/ vol) ethanol, $30 \mathrm{~s}$ in distilled water, 2 minutes in hematoxylin, rinse in running water, $10 \mathrm{~s}$ High Def, rinse in running water, $10 \mathrm{~s}$ in bluing agent, rinse in running water, 10 dips in eosin Y, $2 \times 1$ minutes in $95 \%$ (vol/vol) ethanol, $3 \times 1$ minutes in $100 \%$ ethanol, $3 \times 1 \mathrm{~min}$ in xylene.

10. Immediately place three or four drops of Cytoseal on slides and cover with coverslips. Allow glue to dry for at least $8 \mathrm{~h}$ or overnight.

11. Assess tumor content on the slides. 


\section{Box 2: Implantation from DMSO}

If a line has been electively frozen (DMSO), the following steps can be followed to reimplant the tumor from the sample stored in DMSO at step 7.

1. Keep tube frozen until ready to implant tissue CRITICAL STEP Minimize the time for which the tissue is at room temperature while on DMSO, as this will reduce viability and decrease chances of engraftment.

2. Thaw DMSO tube until $\sim 80 \%$ of solution has melted and place tissue in a 150 petri dish containing $\sim 10 \mathrm{~mL}$ of $1 \%$ ( $\mathrm{vol} / \mathrm{vol}$ ) pen-strep in PBS to rinse.

3. Implant into mice as described in steps $10-25$ of the main procedure. 

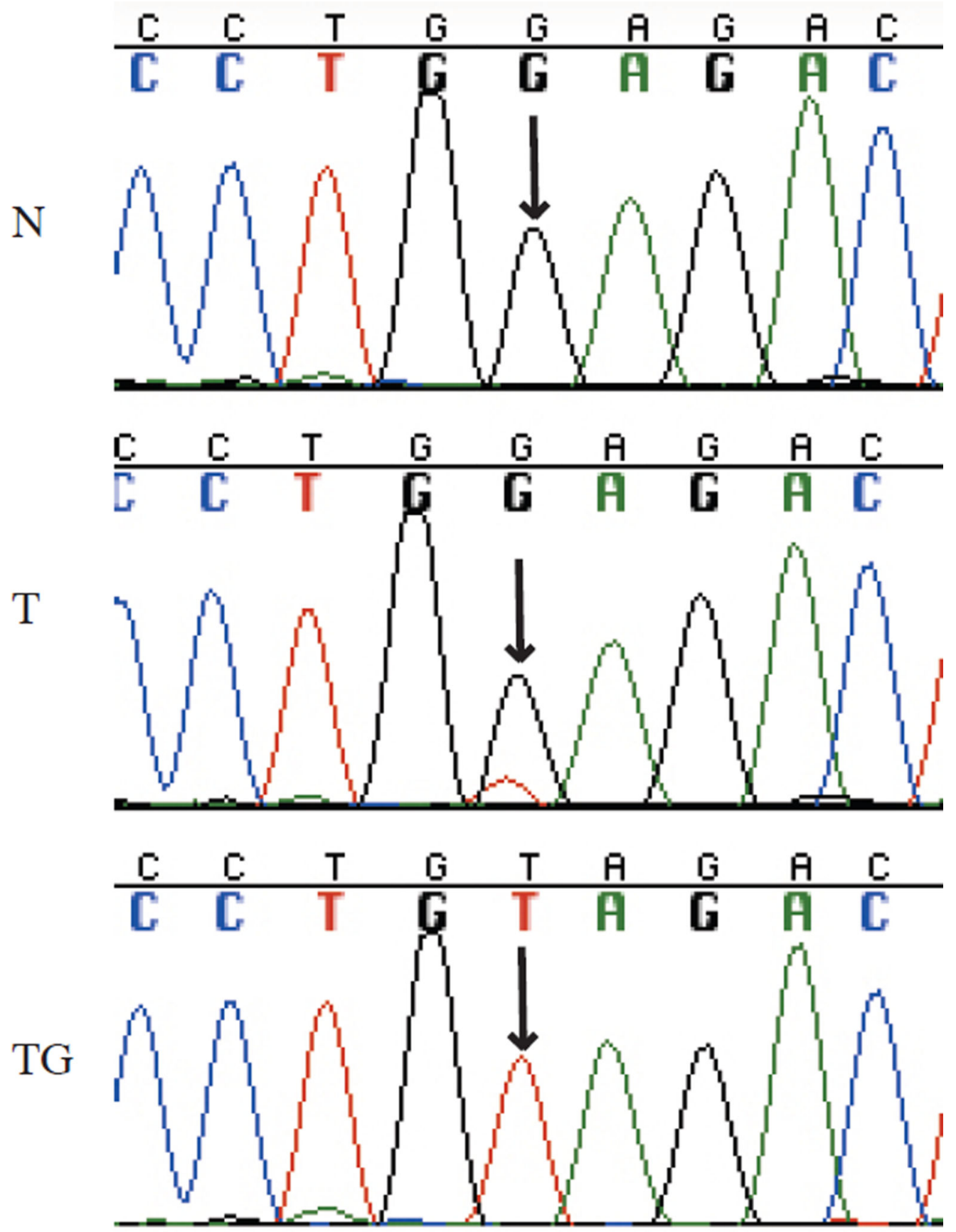

Figure 1.

Chromatogram showing VHL (encoding von Hippel-Lindau tumor suppressor, E3 ubiquitin protein ligase) mutant allele enrichment in TGs. Normal (N), tumor (T), and TG tissue. Arrows point to mutated nucleotide. Data obtained as described in refs. 24, 25. 


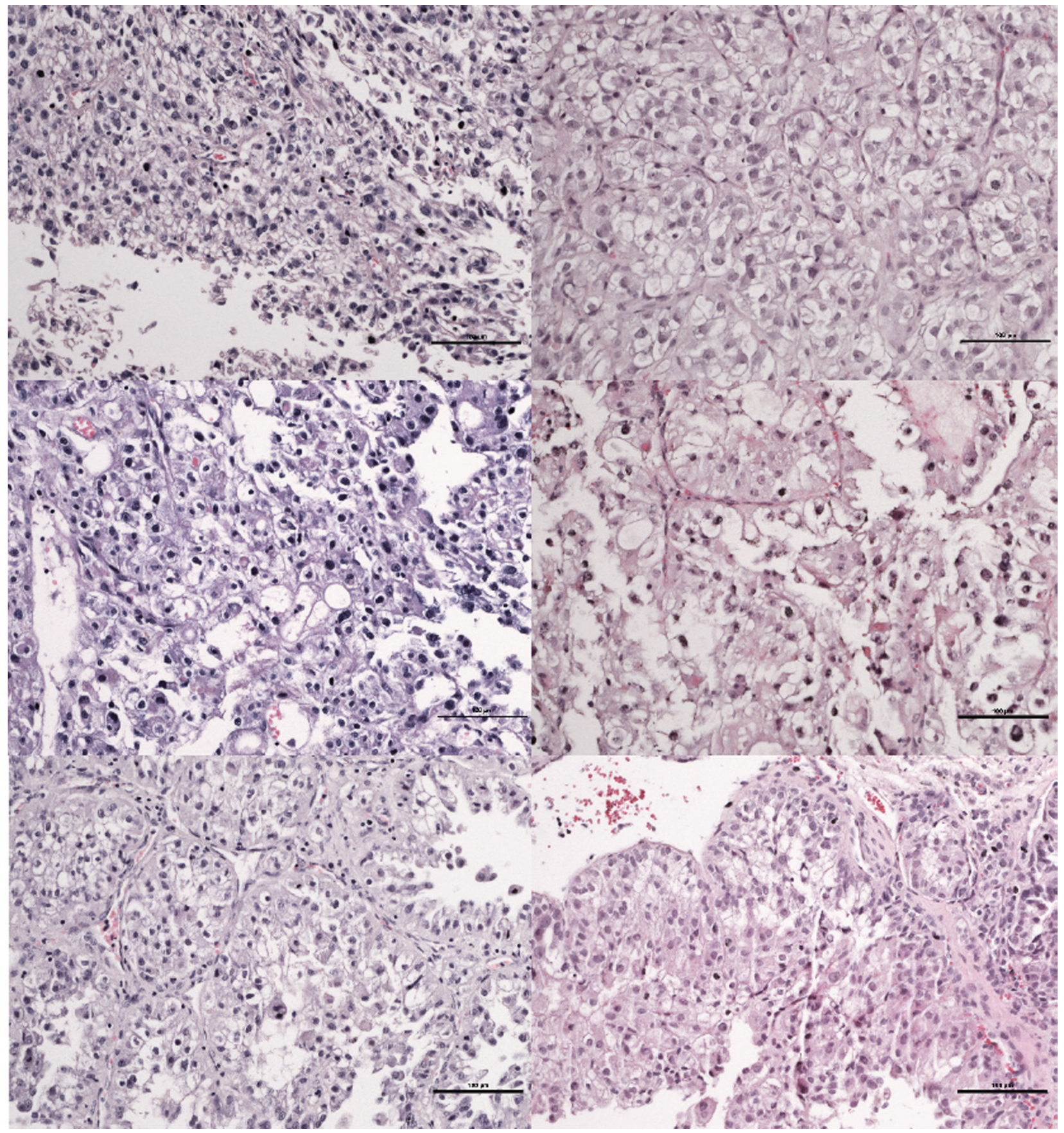

Figure 2.

Matched patient (left) and TG tumors (right) for three different clear cell RCC cases. Note that despite the shared histology, there are architectural and cellular differences and these are preserved in TGs. Scale bars $100 \mu \mathrm{m}$. 


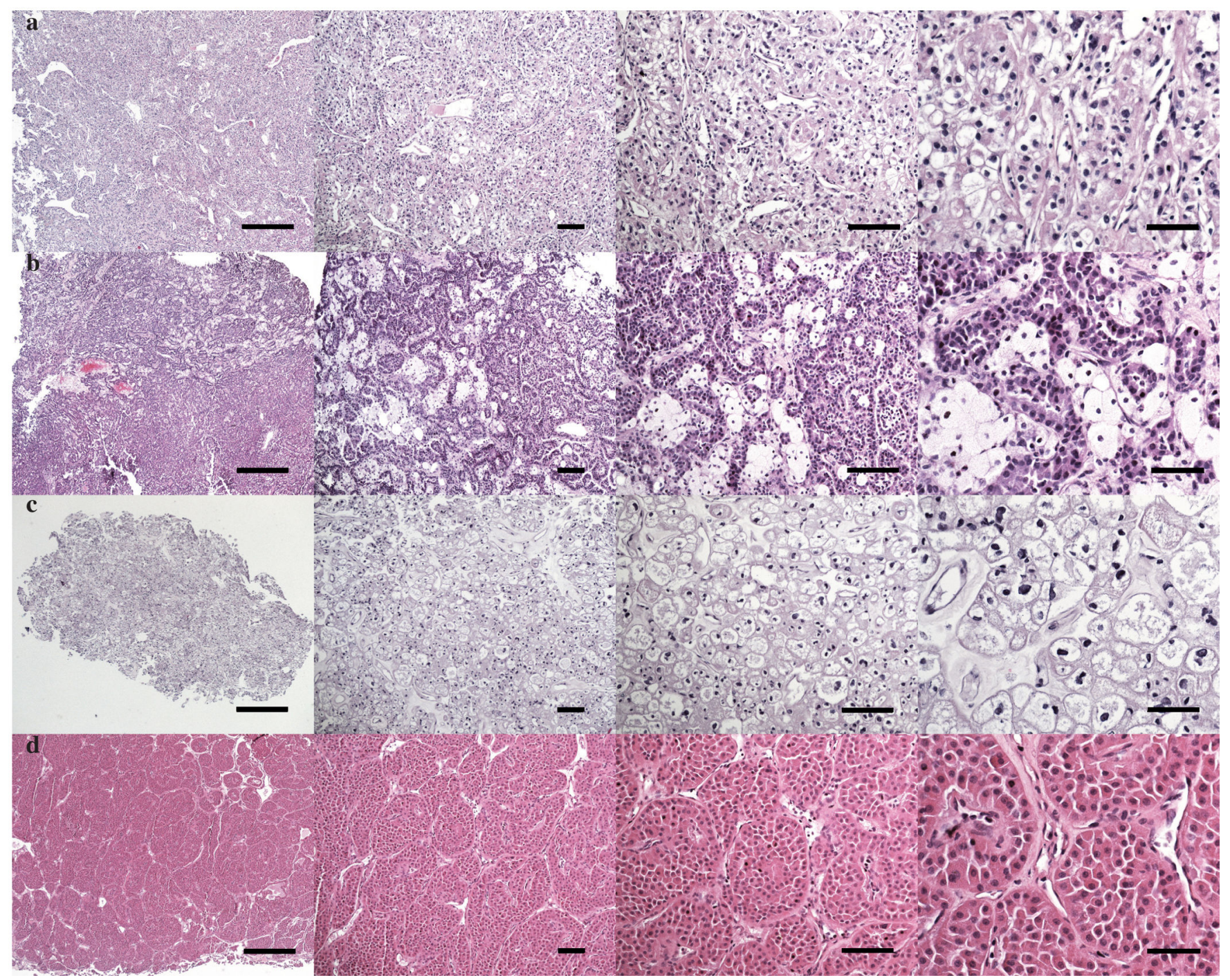

Figure 3.

Identifying kidney tumors under the microscope. a) Clear cell b) papillary c) chromophobe

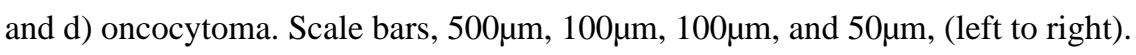




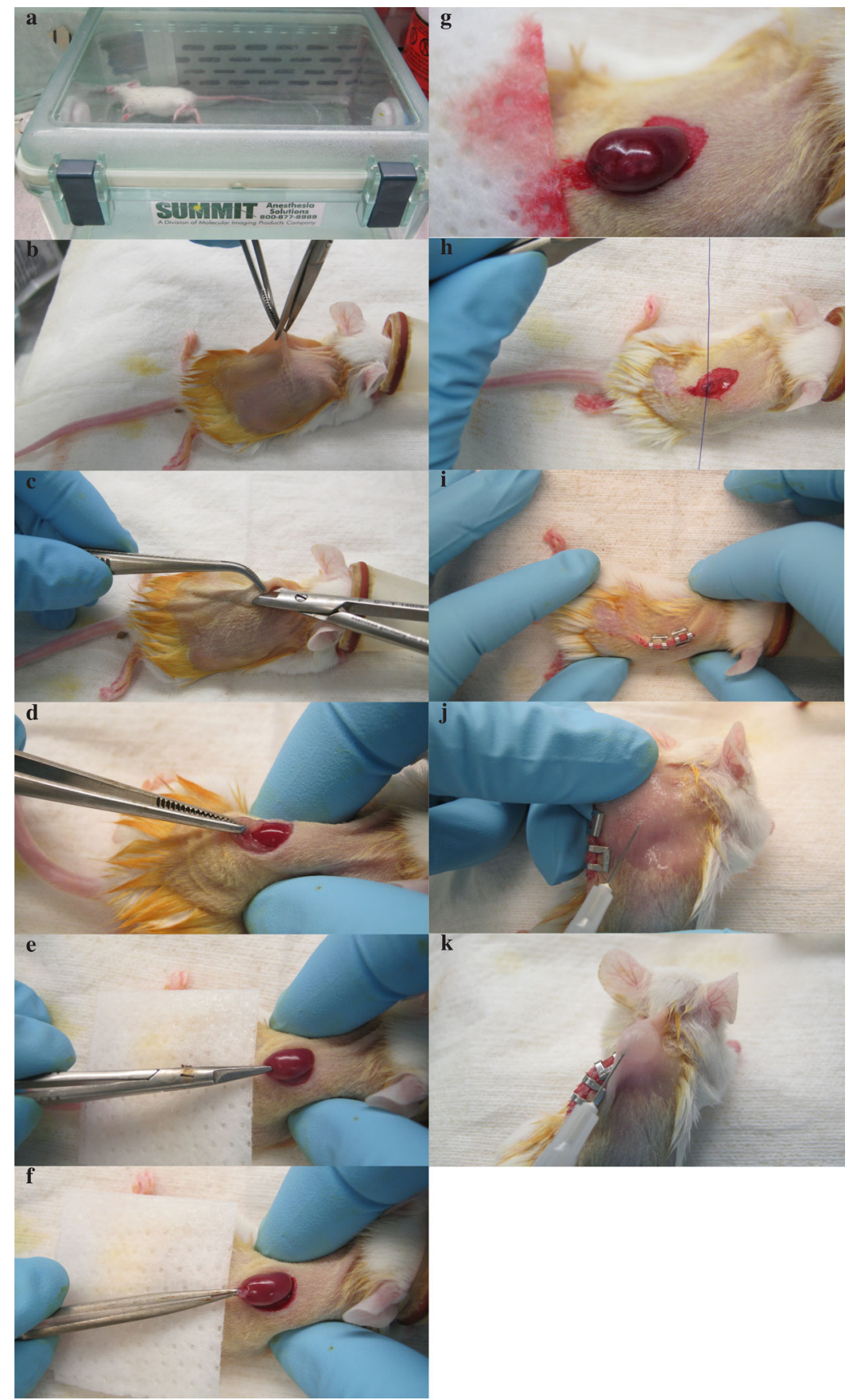

Figure 4.

Renal capsule implantation. a) Anesthetized mouse in induction chamber. b) Dorsal incision of skin. c) Blunt dissection. d) Proper placement of index finger and thumb for exteriorizing kidney. e) Small incision on renal capsule prior to tumor implantation. f) Tumor implantation underneath renal capsule. g) Visual inspection of tumor underneath renal capsule to ensure adequate vascular supply. h) Suturing body wall after placement of kidney back in body cavity. i) Stapled skin at the end of surgical procedure. j) Pinching of scruff 
prior to buprenorphine administration. k) Subcutaneous buprenorphine administration. All mouse experiments were approved by UT Southwestern Medical Center's IACUC. 


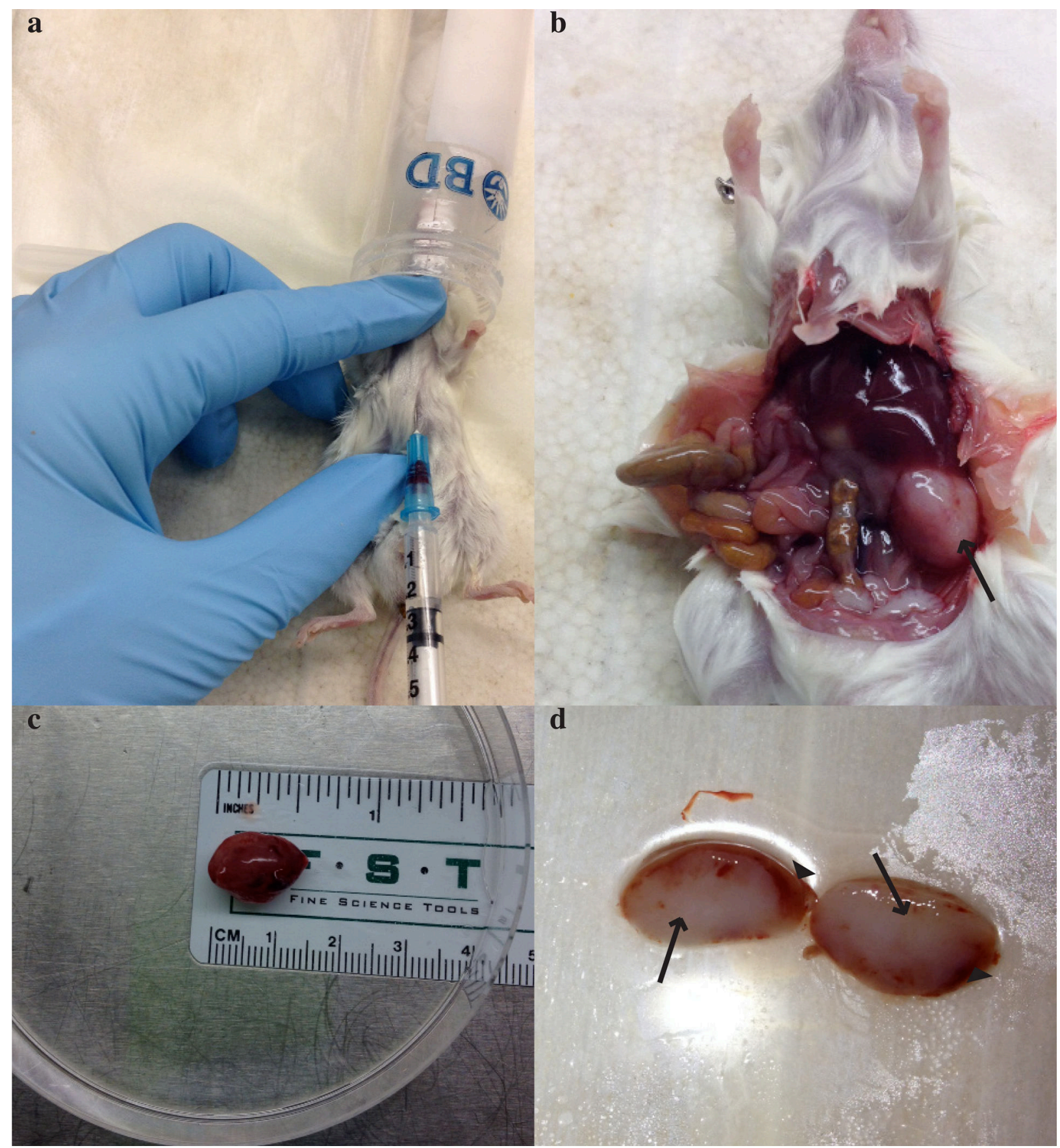

Figure 5.

Harvesting tissue from a tumor-bearing mouse. a) Cardiac puncture procedure. b) Dead mouse with exposed organs. Arrow marks tumor growing on left kidney. c) Tumor on petri dish with ruler underneath the plate to record size. d) Bisected kidney. Arrows mark the tumor and arrow heads point at the normal kidney. All mouse experiments were approved by UT Southwestern Medical Center's IACUC. 


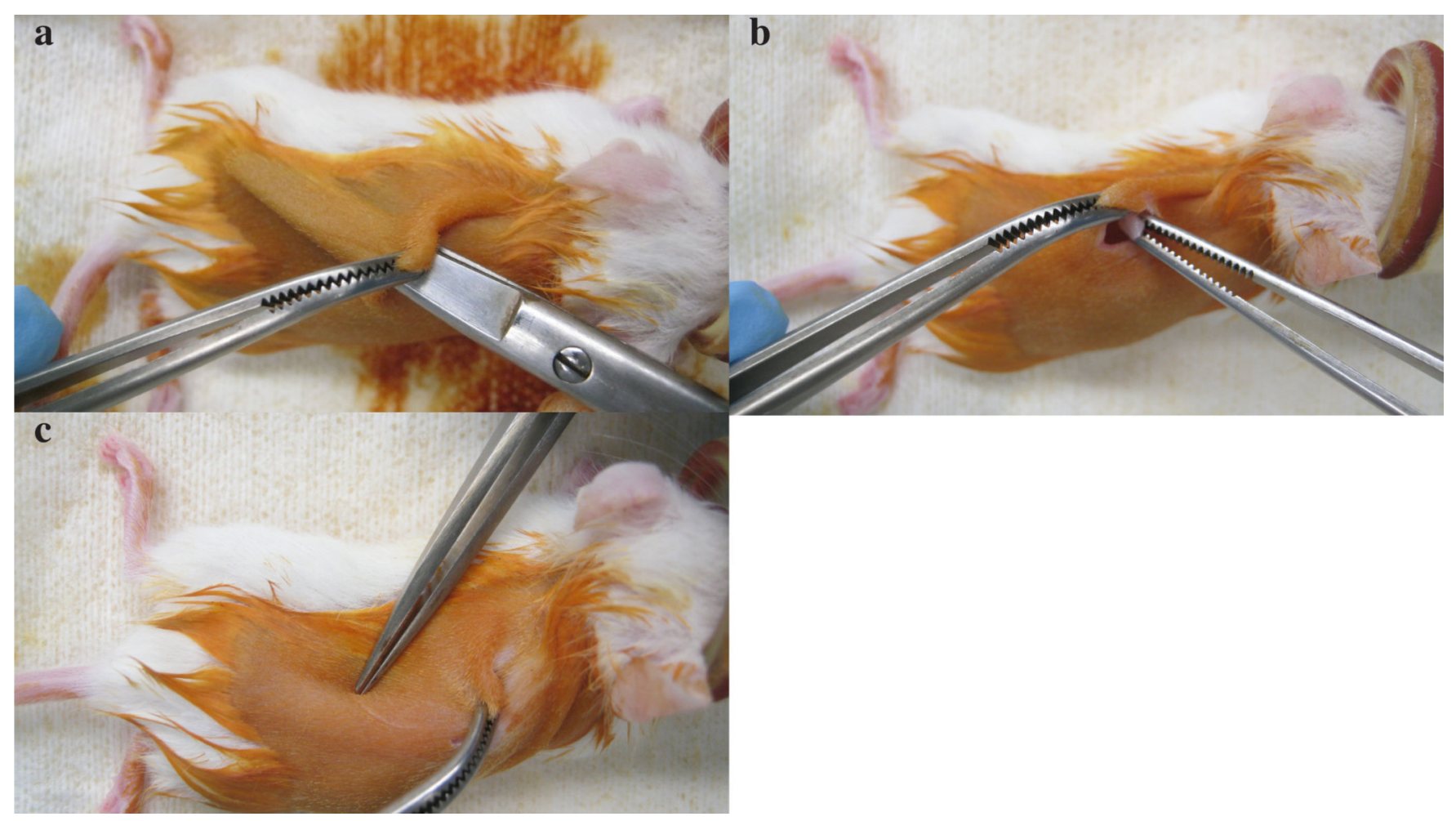

Figure 6.

Subcutaneous implantation for drug trials. a) Blunt dissection for s.c. implantation. b) Introduction of tumor tissue underneath the skin. c) Positioning of tumor fragment once underneath the skin. All mouse experiments were approved by UT Southwestern Medical Center's IACUC. 


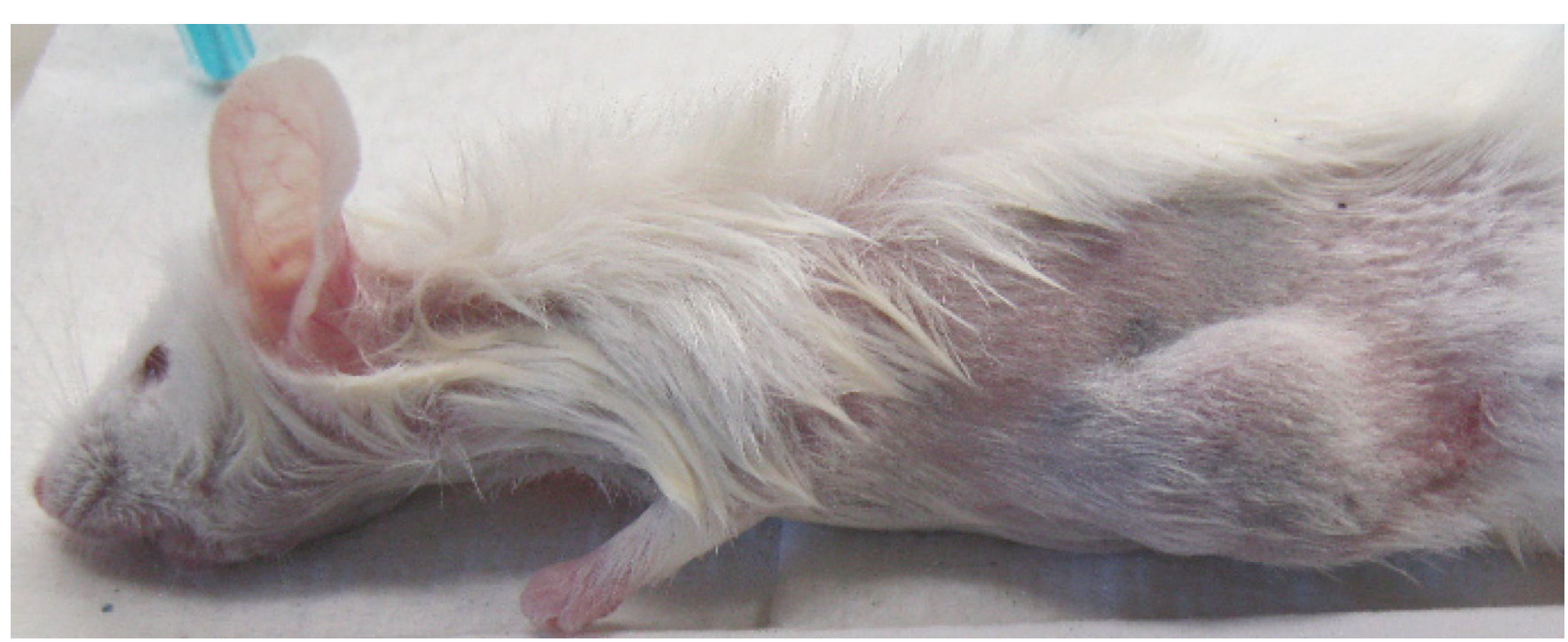

Figure 7.

Subcutaneous tumor after euthanasia of drug trial mouse. All mouse experiments were approved by UT Southwestern Medical Center's IACUC. 


\section{Table 1}

Troubleshooting

\begin{tabular}{|c|c|c|c|}
\hline Step & Problem & Possible Reason & Solution \\
\hline 16 & $\begin{array}{l}\text { Cannot locate or } \\
\text { exteriorize the } \\
\text { kidney }\end{array}$ & Incision is too low or too high & $\begin{array}{l}\text { Use the hump on the back as marker. At the highest point, move } 2 \\
\text { mm to the left. This is roughly the location of the left kidney. It is } \\
\text { best to implant the tumor fragments on the left kidney because the } \\
\text { lobe of the liver is placed above the right kidney, making it difficult } \\
\text { to exteriorize. }\end{array}$ \\
\hline 19 & $\begin{array}{l}\text { Renal capsule starts } \\
\text { to tear }\end{array}$ & $\begin{array}{l}\text { Kidney has been exposed too long } \\
\text { (>10 min) and the capsule has become } \\
\text { dehydrated }\end{array}$ & $\begin{array}{l}\text { Moisten with } 1 \%(\mathrm{vol} / \mathrm{vol}) \text { pen-strep solution in PBS. If capsule has } \\
\text { split down the kidney, it is no longer suitable for implantation }\end{array}$ \\
\hline 28 & $\begin{array}{l}\text { Cannot get enough } \\
\text { blood through } \\
\text { cardiac puncture }\end{array}$ & $\begin{array}{l}\text { Heart may have been missed or } \\
\text { punctured, causing internal bleeding }\end{array}$ & $\begin{array}{l}\text { Open the chest cavity and puncture right atrium of heart to draw } \\
\text { blood }\end{array}$ \\
\hline 35 & $\begin{array}{l}\text { S.c. tumors are not } \\
\text { growing }\end{array}$ & $\begin{array}{l}\text { Not all tumors grow s.c. In our } \\
\text { experience } \sim 15 \% \text { of tumors that grow } \\
\text { orthotopically do not grow s.c. }\end{array}$ & $\begin{array}{l}\text { Implant three or four mice before implanting a large number for a } \\
\text { drug trial in order to assess tumor growth s.c. As an alternative, } \\
\text { consider implanting orthotopically and measuring tumor growth with } \\
\text { ultrasound }\end{array}$ \\
\hline
\end{tabular}

